\title{
Review Article \\ The CCN Family Proteins: Modulators of Bone Development and Novel Targets in Bone-Associated Tumors
}

\author{
Po-Chun Chen, ${ }^{1,2}$ Hsu-Chen Cheng, ${ }^{3}$ Shun-Fa Yang, ${ }^{2,4}$ \\ Chiao-Wen Lin, ${ }^{5,6}$ and Chih-Hsin Tang ${ }^{1,7,8}$ \\ ${ }^{1}$ Graduate Institute of Basic Medical Science, China Medical University, Taichung 40402, Taiwan \\ ${ }^{2}$ Department of Medical Research, Chung Shan Medical University Hospital, Chung Shan Medical University, Taichung 40201, Taiwan \\ ${ }^{3}$ Department of Life Sciences, National Chung Hsing University, Taichung 40227, Taiwan \\ ${ }^{4}$ Institute of Medicine, Chung Shan Medical University, Taichung 40201, Taiwan \\ ${ }^{5}$ Institute of Oral Sciences, Chung Shan Medical University, Taichung 40201, Taiwan \\ ${ }^{6}$ Department of Dentistry, Chung Shan Medical University Hospital, Taichung 40201, Taiwan \\ ${ }^{7}$ Department of Pharmacology, School of Medicine, China Medical University, Taichung 40402, Taiwan \\ ${ }^{8}$ Department of Biotechnology, College of Health Science, Asia University, Taichung 41354, Taiwan
}

Correspondence should be addressed to

Chiao-Wen Lin; cwlin@csmu.edu.tw and Chih-Hsin Tang; chtang@mail.cmu.edu.tw

Received 12 November 2013; Accepted 19 December 2013; Published 14 January 2014

Academic Editor: Po-Lin Kuo

Copyright (C) 2014 Po-Chun Chen et al. This is an open access article distributed under the Creative Commons Attribution License, which permits unrestricted use, distribution, and reproduction in any medium, provided the original work is properly cited.

The CCN family of proteins is composed of six extracellular matrix-associated proteins that play crucial roles in skeletal development, wound healing, fibrosis, and cancer. Members of the CCN family share four conserved cysteine-rich modular domains that trigger signal transduction in cell adhesion, migration, proliferation, differentiation, and survival through direct binding to specific integrin receptors and heparan sulfate proteoglycans. In the present review, we discuss the roles of the CCN family proteins in regulating resident cells of the bone microenvironment. In vertebrate development, the CCN family plays a critical role in osteo/chondrogenesis and vasculo/angiogenesis. These effects are regulated through signaling via integrins, bone morphogenetic protein, vascular endothelial growth factor, Wnt, and Notch via direct binding to CCN family proteins. Due to the important roles of CCN family proteins in skeletal development, abnormal expression of CCN proteins is related to the tumorigenesis of primary bone tumors such as osteosarcoma, Ewing sarcoma, and chondrosarcoma. Additionally, emerging studies have suggested that CCN proteins may affect progression of secondary metastatic bone tumors by moderating the bone microenvironment. CCN proteins could therefore serve as potential therapeutic targets for drug development against primary and metastatic bone tumors.

\section{Introduction}

The extracellular matrix (ECM) primarily serves as a scaffold for the organization of cells into tissues. However, it has also been recognized as a multifunctional modulator of cellular behavior $[1,2]$. Through direct interaction, ECM proteins could modulate activities of many growth factors, cytokines, chemokines, and extracellular proteins or elicit signal transduction cascades, thus regulating diverse cellular functions. Recently, many studies have focused on a group of matrix proteins known as "matricellular" proteins for their function in extracellular signal modulation and coordination [3]. The CCN family, a small group of such matricellular proteins, is composed of six structurally conserved secreted proteins that have been identified in several biological studies [4-6].

The CCN family is named after its three initially discovered members: cysteine rich 61 (Cyr61, CCN1), connective tissue growth factor (CTGF, CCN2), and nephroblastoma overexpressed (Nov, CCN3) [7]. The CCN family includes three other members, Wnt induced secreted proteins 1-3 also known as CCN4, CCN5, and CCN6. The CCN members 
share approximately $40 \%$ to $60 \%$ amino acid homology and comprise a signal peptide followed by 4 functional domains with 38 conserved cysteine residues [8]. In general, the common structure consists of an $\mathrm{N}$-terminal signal peptide followed by an insulin-like growth factor binding protein domain (IGFBP), a von Willebrand type $C$ repeat (VWC), a thrombospondin type I domain (TSP-1), and a cysteine knot carboxyl terminal (CT) [9]. The CCN proteins regulate cell adhesion, migration, proliferation, and differentiation to modulate variant biological functions including tumorigenesis, chondrogenesis, osteogenesis, angiogenesis, apoptosis, and hematopoiesis [5]. Numerous studies have shown that the biological functions of CCN proteins are mediated through interactions with cell surface receptors such as integrins, heparan sulfate proteoglycans (HSPGs), Notch1, neurotrophic tyrosine kinase receptor type 1 (TrkA), and low-density lipoprotein receptor-related proteins (LRPs). Moreover, CCN proteins could interact with other components outside of the cells such as ECM proteins, including fibronectin and fibulin $1 \mathrm{C}$, and growth factors, including bone morphogenetic proteins (BMPs), tumor growth factor beta (TGF- $\beta$ ), and vascular endothelial growth factor [4].

The CCN family proteins were initially classified as growth factors. However, later studies showed that CCN proteins are matricellular proteins that modify cellular responses to extracellular factors via direct binding to cell surface receptors [5, 10-14]. Importantly, in vivo studies have indicated that aberrant expression of CCN proteins is involved in many diseases, including arthritis, atherosclerosis, fibrosis, diabetic nephropathy, retinopathy, and cancer [15]. Although the CCN proteins were discovered a decade ago, their mechanisms of action remain ambiguous. In the present report, we summarize recent literature that focuses on the regulation and function of CCN proteins in various bone tumors, discuss their potential as diagnostic markers and therapeutic targets, and review the recent therapeutic strategies targeting these proteins.

\section{Receptors of CCN Family Proteins}

CCN proteins were shown in previous studies to exert their function through direct binding to integrins or HSPGs. The interaction between $\mathrm{CCN}$ proteins and integrins was first discovered in 1998 by Kireeva et al. [16]. To date, at least 8 integrins have been demonstrated to interact with $\mathrm{CCN}$ proteins [4], which, however, do not possess the typical integrin binding sequence "RGD." Therefore, the interaction is thought to occur through nontypical binding sites, which is confirmed by site-directed mutagenesis that inhibits the biological activities induced by integrin binding. For example, a GVCTDGR sequence in CT domain of CCN2 interacts with integrin $\alpha 5 \beta 1$ binding site and regulates CCN2-stimulated functions $[17,18]$. In addition, CCN3 has been shown to bind to Notch and regulate myoblast and osteoblast functions $[19,20]$.

Other coreceptors are also involved in $\mathrm{CCN}$ protein signaling regulation. Cell surface HSPGs such as syndecan4, perlecan, decorin, and biglycan have been reported to regulate CCN protein function in human fibroblasts [21-25]. CCN2 could also bind to coreceptors of the Wnt receptor LDL-receptor related protein 6 (LRP6) and LRP1 through variant modules $[26,27]$. Moreover, Edwards et al. reported that CCN2 binds to TrkA (also known as neurotrophic tyrosine kinase receptor type 1) (NTRK1) in human mesangial and glioma cells $[28,29]$ and that TrkA serves as a coreceptor with integrins in this interaction. In summary, the complexity of receptors and coreceptors contributes to the unique activities and functions of CCN proteins in various cell types.

\section{Functions of CCN Family Proteins}

3.1. Adhesion and Migration. As expected from matricellular proteins modulating ECM signaling, the most familiar functions of CCN proteins are their roles in cell adhesion and migration. For example, CCN1 and CCN2 regulate adhesion in several types of cells [30]. In human skin fibroblasts, CCN1and CCN2-regulated cell attachment is mediated through integrin $\alpha 6 \beta 1$ and HSPGs [31]. In vascular smooth muscle cells, endothelial cells, and fibroblasts, CCN3 promotes cell adhesion through integrins and HSPGs [5]. Despite the lack of the RGD motif, the canonical binding motif for integrins, CCN3 could interact with many integrin receptors such as integrin $\alpha 6 \beta 1, \alpha 5 \beta 1, \alpha \mathrm{v} \beta 3, \alpha \mathrm{v} \beta 5, \alpha 2 \beta 1, \alpha 3 \beta 1$, and $\alpha 7 \beta 1$. CCN proteins can mediate cell migration through interaction with cell surface receptors. Previous studies have shown that all CCN proteins could regulate cell migration in many cell types. CCN1, CCN2, and CCN3 proteins promote cell migration in different types of cells [4]. CCN4 is involved in the migration and proliferation of vascular smooth muscle cells [32]. CCN5, however, is an important negative regulator of motility through matrix metalloproteinase (MMP)-2 gene expression modulation [33]. Finally, CCN6 stimulates migration of undifferentiated mesenchymal stroma cells [34].

3.2. Cell Survival and Apoptosis. Adhesion to the ECM is a crucial process to promote cell survival, whereas detachment from the ECM induces rapid cell death. The mechanism of CCN proteins regulating cell fates varies in different cell types. For example, CCN1 can promote cell survival in human umbilical vein endothelial cells through integrin $\alpha \mathrm{v} \beta 3$ [35] but induces fibroblast apoptosis through integrin $\alpha 6 \beta 1$ HSPG syndecan-4 interaction [24]. These results suggest that specific CCN matricellular protein can either induce or suppress apoptosis via variant receptor interaction in a cell type-specific manner.

3.3. Proliferation. The first discovered CCN protein CCN1, also known as Cyr61, was believed to be a classic growth factor. However, later efforts established that CCN1, instead of being a growth factor itself, enhanced the activity of some growth factors such as fibroblast growth factor and platelet-derived growth factor [36]. CCN2 has been demonstrated to induce proliferation of chondrocytes through the MAPK/ERK signaling pathway [37], and knockdown of CCN2 expression inhibits cell proliferation and increases 
apoptosis [38]. CCN3, however, has been reported to have negative regulatory properties, and its abnormal expression is associated with cancer progression [39]. Other studies have otherwise indicated that high $\mathrm{CCN} 3$ expression is associated with increased proliferation rates or tumor promoting potential in many cancer types [40]. The ambiguous effects of $\mathrm{CCN} 3$ therefore require further investigation.

3.4. Angiogenesis. CCN proteins have been suggested as potent angiogenic modulators, with activity mediated by interactions with different integrins and growth factors [41]. Treatments with recombinant CCN1, CCN2, and CCN3 increase angiogenesis in vivo, demonstrated via subcutaneous injection into corneas and the chick chorioallantoic membrane assay [5]. CCN1 and CCN2 play crucial roles in embryonic angiogenesis. Knockdown of CCN1 expression induces cardiovascular defects and is associated with embryonic lethality due to placental vascular inefficiency and compromised blood vessels [42]. CCN2, however, regulates angiogenesis via a different developmental process. In vivo results show that CCN2-null mutant mice show angiogenic deficiency in the growth plates during endochondral bone formation [43]. In addition, CCN3 has been demonstrated as a novel angiogenic regulator acting directly on endothelial cells to stimulate proangiogenic activities and as an angiogenesis inducer in vivo [44]. However, the roles of CCN4, CCN5, and $\mathrm{CCN} 6$ in angiogenesis remain poorly understood.

3.5. Inflammation. Abundant evidences indicate that $\mathrm{CCN}$ proteins are involved in inflammatory responses [45]. CCN protein expression is tightly regulated by different inflammatory mediators, including cytokines such as tumor necrosis factor alpha (TNF- $\alpha$ ), interleukin (IL)- $1 \beta$, and TGF- $\beta$, or by small factors such as prostaglandins, nitric oxide, histamine, and serotonin. Moreover, viral or bacterial infection also induces CCN proteins expression. Recognized as being encoded by an immediate early gene induced by environmental changes, $\mathrm{CCN}$ proteins subsequently regulate activity and expression of inflammatory cytokines and chemokines. For example, a recently published study showed that CCN1 promoted a proinflammatory program in murine macrophages. Bai et al. reported that CCN1 induced the expression of proinflammatory cytokines such as TNF- $\alpha$, IL1- $\alpha$, IL1- $\beta$, and IL-6; chemokines; and regulators of oxidative stress and inhibited the expression of anti-inflammatory factors such as TGF- $\beta$ [46]. In addition, numerous studies have demonstrated a pivotal role of CCN proteins in chronic inflammatory diseases such as atherosclerosis, rheumatoid arthritis, inflammatory kidney diseases, and Alzheimer disease [45]. Therefore, CCN proteins may be classified as a new class of inflammatory regulators.

\section{The Role of CCN Proteins in Bone}

Bone is a complex tissue composed of two major cell types, bone resorption osteoclasts and bone formation osteoblasts, responsible for bone remodeling. Another cell population resident in the cartilage is chondrocytes. Abundant evidence suggests that $\mathrm{CCN}$ proteins regulate the differentiation of these cells (osteoblasts, osteoclast, and chondrocyte) [47]. In addition, CCN proteins are highly regulated during chondrogenic and osteogenic differentiation in mesenchymal stem cells [48-50]. However, CCN proteins can play either a positive or a negative regulatory role in skeletogenesis, which has been demonstrated both in vitro and in vivo $[5,51]$.

$\mathrm{CCN} 1$ has been detected in mouse limb bud mesenchymal cells during chondrogenesis and has been shown to promote chondrogenic differentiation through expression of type II collagen [52]. In another study, the tightly regulated CCN1 expression was shown to be involved in Wnt3A-induced osteoblast differentiation of mesenchymal stem cells [50]. Moreover, $\mathrm{CCN} 1$ has been shown to promote osteogenesis by increasing osteoblast differentiation while inhibiting osteoclast formation [53].

$\mathrm{CCN} 2$ is the most discussed member of the CCN protein family, accounting for approximately 50\% of all reports published on the subject [54], most of which focus on the role of CCN2 in fibrosis and osteo/chondrogenesis. These reports indicate that $\mathrm{CCN} 2$ plays a crucial role in embryogenesis and skeletogenesis. For example, CCN2 has been shown to promote proliferation, chondrogenic differentiation, and chondrocyte maturation $[55,56]$. CCN2 expression is high in the vascular tissue and maturing chondrocytes of the embryo and is important for cell proliferation and matrix remodeling during chondrogenesis [43]. In addition, CCN2 could also interact with many BMPs, important bone formation regulators, to regulate chondrocyte proliferation and differentiation $[57,58]$. Finally, in vivo results have shown that CCN2 deficiency leads to skeletal dysmorphisms caused by impaired chondrocyte proliferation and reduced ECM composition in the growth plate [43].

Reported results on $\mathrm{CCN} 3$, however, are contradicting. CCN3 has been found to inhibit osteoblastogenesis and cause osteopenia, through antagonizing BMP-2, and Wnt activity in mice [59]. CCN3 has also been shown to inhibit osteoblast differentiation by neutralizing BMP2, a well-known enhancer of osteoblastogenesis in MC3T3 osteoblast precursor cells, in in vivo studies [20]. In another study, CCN3 showed antagonistic properties, inhibiting osteoblastogenesis and osteoblastic function through BMP2 neutralization and impairment of Wnt 3 signaling [60]. In summary, these results suggest CCN3 as a negative regulator of osteoblastogenesis through multiple mechanisms including BMP2 and Wnt signaling or via activation of the Notchl pathway. In contrast, a recent study has indicated that $\mathrm{CCN} 3$ promotes osteoblast differentiation and bone mineralization by upregulation of BMP-4, a wellknown inducer of osteoblast differentiation [61]. In that study, a lower dose CCN3 $(30 \mathrm{ng} / \mathrm{mL})$ increased osteoblast differentiation whereas a higher dose $(600 \mathrm{ng} / \mathrm{mL})$ exhibited an opposite phenomenon, suggesting concentration-dependent mechanisms of action for CCN3.

Studies on the other three members of the CCN family are scarce, except for a report on CCN6. In that study, point mutations in CCN6 were shown to relate to the autosomal recessive skeletal disease progressive pseudorheumatoid dysplasia, a human disease resulting in progressive degeneration of articular cartilage [54]. 
TABLE 1: CCN proteins in primary bone cancers.

\begin{tabular}{|c|c|c|c|c|}
\hline Cancer & CCN proteins & Expression level & Experimental observation & References \\
\hline \multirow{4}{*}{ Osteosarcoma } & \multirow{2}{*}{ CCN1 } & \multirow{2}{*}{ Higher } & $\begin{array}{l}\text { CCN1 associates with poor prognosis, tumour stage, metastasis and } \\
\text { mortality }\end{array}$ & {$[62]$} \\
\hline & & & $\begin{array}{l}\text { CCN1 knockdown inhibits osteosarcoma cell invasion, migration, and lung } \\
\text { metastases }\end{array}$ & {$[63]$} \\
\hline & CCN3 & Higher & $\begin{array}{l}\text { CCN3 expression level is associated with higher risk to develop lung } \\
\text { metastases }\end{array}$ & {$[64]$} \\
\hline & $\mathrm{CCN} 4$ & Higher & $\begin{array}{l}\text { CCN4 associates with tumor stage and enhances the migration of } \\
\text { osteosarcoma cells by increasing MMP- } 2 \text { and MMP-9 expression }\end{array}$ & [65] \\
\hline \multirow{3}{*}{ Ewing's sarcoma } & \multirow{3}{*}{ CCN3 } & Higher & $\begin{array}{l}\text { CCN3 is expressed in approximately } 30 \% \text { of Ewing's sarcomas and } \\
\text { associated with lower survival rate }\end{array}$ & {$[64]$} \\
\hline & & & $\begin{array}{l}\text { High expression of } \mathrm{CCN} 3 \text { is detected in recurrences and metastases when } \\
\text { compared to the primary tumor. }\end{array}$ & {$[66]$} \\
\hline & & $\mathrm{N} / \mathrm{A}$ & $\begin{array}{l}\text { Forced expression of CCN3 shows decreased cell proliferation while } \\
\text { increased migration and invasion }\end{array}$ & {$[67]$} \\
\hline \multirow{5}{*}{ Chondrosarcoma } & $\mathrm{CCN} 1$ & $\mathrm{~N} / \mathrm{A}$ & $\begin{array}{l}\text { CCN1 enhances the migration of chondrosarcoma cells by increasing } \\
\text { MMP-13 expression }\end{array}$ & {$[68]$} \\
\hline & $\mathrm{CCN} 2$ & N/A & $\mathrm{CCN} 2$ increases the migration through upregulating MMP-13 expression & [69] \\
\hline & $\mathrm{CCN} 3$ & N/A & $\begin{array}{l}\text { CCN3 increases the migration and expression of matrix metalloproteinase } \\
\text { MMP-13 }\end{array}$ & {$[70]$} \\
\hline & $\mathrm{CCN} 4$ & $\mathrm{~N} / \mathrm{A}$ & $\begin{array}{l}\text { CCN4 enhances the migration of chondrosarcoma cells by increasing } \\
\text { MMP- } 2 \text { expression }\end{array}$ & {$[71]$} \\
\hline & CCN6 & $\mathrm{N} / \mathrm{A}$ & $\begin{array}{l}\text { CCN6 enhances the migration of chondrosarcoma cells by increasing } \\
\text { ICAM-1 expression }\end{array}$ & {$[72]$} \\
\hline
\end{tabular}

\section{The Role of CCN Family Proteins in Primary Bone Cancers}

$\mathrm{CCN}$ proteins are tightly regulated in osteo/chondrogenic cell lineages and are involved in skeletogenesis. Abnormal levels or altered forms of CCN proteins are associated with tumor progression. We hereby discuss the correlation between CCN proteins and primary bone cancers (Table 1).

5.1. Osteosarcoma. Osteosarcoma is the most common primary bone tumor found in children and young adults. The existing literature suggests that osteosarcoma might originate from mesenchymal cells with osteoblastic features [73-75]. The CCN1 expression level in osteosarcoma biopsies has been shown to correlate with poor prognosis, regardless of metastatic or nonmetastatic disease. Moreover, an in vivo murine model showed that overexpression of CCN1 in the low-metastatic human SaOS-2 osteosarcoma cell line increased cell proliferation and promoted lung metastasis [62]. Fromigue et al. also demonstrated that CCN1 protein expression was higher in human osteosarcoma than in normal bone tissue and was most highly expressed in metastatic tissues. They also found that CCN1 knockdown inhibited in vitro osteosarcoma cell invasion and migration as well as in vivo lung metastases in mice [63]. Therefore, these results demonstrate great potential for $\mathrm{CCN1}$ as a novel prognosis marker and therapeutic target in osteosarcoma. In addition, another study showed that CCN3 was expressed in primary tumors of osteosarcoma patients and that a high CCN3 expression level was associated with an increased risk of developing lung metastases [64]. CCN4 also showed similar correlation like CCN1 and CCN3 in osteosarcoma. In our previous work, we show that the expression of CCN4 in osteosarcoma patients was significantly higher than that in normal bone and corrected with tumor stage. CCN4 increases cell motility through upregulating matrix metalloproteinase (MMP)-2 and MMP-9 expression [65].

5.2. Ewing Sarcoma. Ewing sarcoma is the second most common malignant bone tumor that mainly occurs in children. CCN3 is expressed in approximately 30\% of all Ewing sarcoma cases, and its expression is associated with a lower survival rate [64]. In a study by Benini et al., overexpression of CCN3 led to decreased in vitro cell proliferation and soft-agar growth in Ewing sarcoma cells and in vivo tumorigenicity in nude mice. However, these Ewing sarcoma cells showed increased migration and invasion in Matrigel [67]. Finally, an immunohistochemistry study on 170 human Ewing sarcoma specimens showed that the expression of CCN3 was higher in recurrences and metastases than in primary tumors. The same study also suggested that a low level of CCN3 expression was associated with better patient prognosis [66].

5.3. Chondrosarcoma. Chondrosarcoma is the second most common malignancy of the bone, associated with a poor response to currently used chemotherapy and radiation treatment, making chondrosarcoma management a complicated challenge $[76,77]$. All CCN proteins have been 
TABLE 2: CCN proteins in metastatic bone cancers.

\begin{tabular}{|c|c|c|c|c|}
\hline Cancer & CCN proteins & Expression level & Expreimental observation & References \\
\hline \multirow{11}{*}{ Breast cancer metastasize to bone } & \multirow{3}{*}{$\mathrm{CCN} 1$} & Higher & $\begin{array}{l}\text { CCN1 associates with poor prognosis, nodal involvement, } \\
\text { and metastatic disease }\end{array}$ & {$[79]$} \\
\hline & & N/A & $\begin{array}{l}\text { Zoledronic acid downregulates CCN1, thus inhibits tumor } \\
\text { growth }\end{array}$ & {$[80]$} \\
\hline & & N/A & $\begin{array}{l}\text { Anti-CCN1 neutralizing antibody suppresses primary } \\
\text { tumor growth and spontaneous lymph node metastasis in } \\
\text { vivo }\end{array}$ & {$[81]$} \\
\hline & \multirow{4}{*}{$\mathrm{CCN} 2$} & Higher & $\begin{array}{l}\text { The expression of CCN2 is higher in breast cancer bone } \\
\text { metastases when compared to normal breast tissue }\end{array}$ & {$[82]$} \\
\hline & & Higher & $\begin{array}{l}\text { CCN2 is significantly overexpressed in metastatic tumor } \\
\text { cells as compared to disseminated tumor cells }\end{array}$ & {$[83]$} \\
\hline & & N/A & $\begin{array}{l}\text { CCN2 is crucial for osteolytic metastasis and is induced by } \\
\text { PKA- and PKC-dependent activation of ERK1/2 signaling } \\
\text { by PTHrP }\end{array}$ & {$[84]$} \\
\hline & & Higher & $\begin{array}{l}\text { CCN } 2 \text { expression is further increased by the prometastatic } \\
\text { cytokine TGF } \beta\end{array}$ & {$[85]$} \\
\hline & \multirow{3}{*}{$\mathrm{CCN} 3$} & Lower & $\begin{array}{l}\text { Expression of CCN3 is lower in tumor when compared to } \\
\text { normal specimens }\end{array}$ & {$[79]$} \\
\hline & & Higher & $\begin{array}{l}\text { CCN3 is highly expressed in the bone metastases when } \\
\text { compared with the other metastases (lung, brain, and } \\
\text { liver) }\end{array}$ & {$[86]$} \\
\hline & & Higher & $\begin{array}{l}\text { CCN3 is highly expressed in bone metastasis samples from } \\
\text { breast cancer patients }\end{array}$ & {$[87]$} \\
\hline & CCN6 & Lower & $\begin{array}{l}\text { CCN6 expression is inversely correlated with invasive } \\
\text { breast carcinomas }\end{array}$ & {$[88]$} \\
\hline \multirow{4}{*}{ Prostate cancer metastasize to bone } & $\mathrm{CCN} 1$ & N/A & $\begin{array}{l}\text { CCN1 increases tumorigenesis and metastasis of prostate } \\
\text { cancer cells }\end{array}$ & [89] \\
\hline & \multirow[t]{2}{*}{ CCN3 } & N/A & $\begin{array}{l}\text { Knockdown of CCN3 expression decreases cell migration } \\
\text { in vitro and tumor growth in bone and bone metastasis in } \\
\text { vivo }\end{array}$ & {$[90]$} \\
\hline & & Higher & $\begin{array}{l}\text { CCN3 expression levels are higher in bone metastasis } \\
\text { patients and positively correlated with malignancy in } \\
\text { human prostate cancer cells }\end{array}$ & {$[91]$} \\
\hline & CCN4 & Higher & $\begin{array}{l}\text { Higher expression level of } \mathrm{CCN} 4 \text { has been found in the } \\
\text { tissues and sera of prostate cancer patients in early stages }\end{array}$ & {$[92]$} \\
\hline
\end{tabular}

demonstrated to be involved in chondrosarcoma progression and malignancy except for CCN5. The CCN proteins have been shown to promote cell migration through upregulation of various genes such as MMP-2, MMP-13, and intercellular adhesion molecule 1 (ICAM-1) [68-72]. These results suggest that $\mathrm{CCN}$ proteins might regulate common biological functions in chondrosarcoma. Other cellular functions regulated by CCN proteins such as adhesion, proliferation, survival, apoptosis, and angiogenesis may also be involved in $\mathrm{CCN}$ protein-regulated tumorigenesis. Interestingly, CCN proteins promote expression of MMPs, important regulators of ECM, which might explain the prometastatic effects exerted by the CCN family. The tumor microenvironment could also significantly influence chondrosarcoma malignancies. A previous study indicated that the tumor microenvironment could affect CCN2 gene expression in Swarm rat chondrosarcoma tumors, suggesting that CCN2 may play a role in chondrosarcoma development and progression [78].

\section{The Role of CCN Family Proteins in Metastatic Bone Cancers}

Bone metastasis is a common complication of advanced cancer, occurring when cancer cells from the primary tumor spread to the bone. Prostate, breast, and lung cancers are most likely to result in bone metastasis. As $\mathrm{CCN}$ proteins have important roles in the differentiation and function of bone resident cells, they have been implicated in the progression of bone metastases from other cancers (Table 2).

6.1. Breast Cancer Metastasis to the Bone. Breast cancer shows a high predilection for metastasis to the bone, causing bone pain, pathological fractures, hypercalcemia, spinal cord compression, and immobility [93]. In a cohort of 122 human breast tumors and 32 normal breast specimens, significantly elevated levels of CCN1 were shown to be associated with poor prognosis, nodal involvement, and metastatic disease [79]. CCN1 is a potent proangiogenic molecule, 
and a previously published study suggested the critical role of CCN1 in the Hedgehog-influenced proangiogenic tumor microenvironment [94]. CCN1 has also been recommended as a candidate target for breast cancer bone metastases. Espinoza et al. found that zoledronic acid, a bisphosphonate currently used to treat breast cancer bone metastases, downregulated CCN1, thus inhibiting tumor growth [80]. Moreover, the anti-human CCN1 antibody, denoted as 093G9, was shown to inhibit breast cancer cell migration and invasion through upregulation of the MMP inhibitors TIMP1 and TIMP2. In vivo mouse model results showed that 093G9 also inhibited primary tumor growth and spontaneous lymph node metastases [81].

CCN2 was found to be overexpressed in tumor cells from human bone metastases compared to a normal human epithelial cell line [82]. In addition, another report indicated that CCN2 was significantly overexpressed in metastatic tumor cells compared to disseminated tumor cells [83], further supporting the previously mentioned evidence. An in vivo mouse model study was performed to investigate the role of CCN2 in osteolytic metastasis by breast cancer cells. The results showed that CCN2 was crucial for osteolytic metastasis and was induced by protein kinase A- and protein kinase C-dependent activation of ERK1/2 signaling by parathyroid hormone-related protein (PTHrP). The authors also found that osteolytic metastasis accompanied by the PTHrP-CCN2 signaling pathway was efficiently abolished by a CCN2 neutralizing antibody [84]. Another previously published study investigated the mechanism of osteolytic bone metastasis by selecting human breast cancer cell line subpopulations with elevated metastatic activity and found that IL-11 and CCN2 expressions were further increased by the prometastatic cytokine TGF $\beta$. These results elucidated a mechanism for the prometastatic activity of these cytokines in the bone [85].

However, studies on CCN3 have reported contradicting results. In a different cohort of 122 human breast tumors and 32 normal breast specimens, the expression of CCN3 was found to be lower in tumor tissues when compared to normal specimens [79]. Interestingly, in another study, a microarray profile derived from 58 breast cancer metastases showed CCN3 to be highly expressed in bone metastases when compared to other metastases (lung, brain, and liver) [86]. Moreover, Véronique et al. found that CCN3 was highly expressed in bone metastasis samples from breast cancer patients. They also demonstrated that $\mathrm{CCN} 3$ increased the bone metastatic potential of $66 \mathrm{cl} 4$ cells, which are breast cancer cells metastasizing to the lungs [87].

The balance between bone formation and resorption is a significant factor in the development of bone metastasis. In accordance with this opinion, CCN3 was shown to impair osteoblast differentiation and affect receptor activator of NF$\kappa \mathrm{B}$ ligand (RANKL)/osteoprotegerin ratios of osteoblasts, thereby enhancing osteoclastogenesis. CCN3 was also shown to promote osteoclast differentiation through a RANKLdependent pathway, which involves calcium oscillations and nuclear factor of activated T-cell nuclear translocation [87].

In contrast, studies on CCN6 indicated that it inhibited breast cancer metastasis. In clinical specimens, CCN6 expression was shown to inversely correlate with invasive breast carcinomas. Moreover, CCN6 was shown to inhibit invasion and metastasis of breast cancer in vivo. The mechanism of CCN6-inhibited breast cancer progression was shown to be mediated by the BMP4/TAK1/p38 pathway, which could induce epithelial-mesenchymal transition, cell invasion, and metastasis [88]. Decline of CCN6 protein expression was demonstrated to sufficiently activate the phosphatidylinositol 3-kinase/Akt signaling pathway, thus promoting growth factor-independent survival that is triggered by resistance to detachment-induced cell death (anoikis) [95]. The role of CCN6 in breast cancer metastasis has been proved. However, the role of CCN6 in bone metastatic breast cancer remains poorly understood and further studies are necessary.

6.2. Prostate Cancer Metastasis to the Bone. Prostate cancer is the most commonly diagnosed malignancy in the United States and other Western countries, and bone metastasis is a common complication associated with advanced prostate cancer [96-98]. Prostate cancer bone metastases are most often characterized as osteoblastic lesions as opposed to osteolytic lesions with decreased bone mineral density. Increasing evidence suggests that prostate cancer cells synchronize the combined osteoclastic and osteoblastic activity occurring in the bone microenvironment [99-101]. However, the role of CCN proteins in prostate cancer metastasis to the bone is discussed relatively scarcely.

CCN1 has been implicated in tumorigenesis and metastasis of prostate cancer cells [89]. CCN1 activates Rasrelated $\mathrm{C} 3$ botulinum toxin substrate 1 and its downstream targets, including phosphorylated c-Jun N-terminal kinase, E-cadherin, and p27 (kipl), key molecules involved in cell growth, migration, and invasion. In vivo mouse model results revealed that $\mathrm{CCN1}$ increased the metastatic potential of prostate cancer cells. The correlation of CCN1 and prostate cancer bone metastases, however, needs to be confirmed.

CCN3 has been demonstrated to have prometastatic potential in prostate cancer in our previous study [90]. We found that CCN3 increased cell migration through the upregulation of ICAM-1 expression. Knockdown of CCN3 expression markedly inhibited cell migration in vitro and tumor growth in bone and bone metastasis in vivo. Moreover, our latest study revealed the critical role of CCN3 in prostate cancer bone metastases [91]. An immunohistochemistry study on normal prostate tissues, primary tumors, and bone metastasis samples obtained from patients revealed that CCN3 expression levels were higher in patients with bone metastasis and positively correlated with malignancy in human prostate cancer cells. In agreement with the study by Véronique et al. [87], our results showed that the prostate cancer-secreted CCN3 induced osteoclastogenesis through a RANKL-dependent pathway. Moreover, the focal adhesion kinase/Akt/p38/NF- $\kappa$ B signaling pathway was found to be involved in CCN3-mediated receptor activator of NF$\kappa \mathrm{B}$ expression and RANKL-dependent osteoclastogenesis. Experiments with intratibia injection of prostate cancer cells 


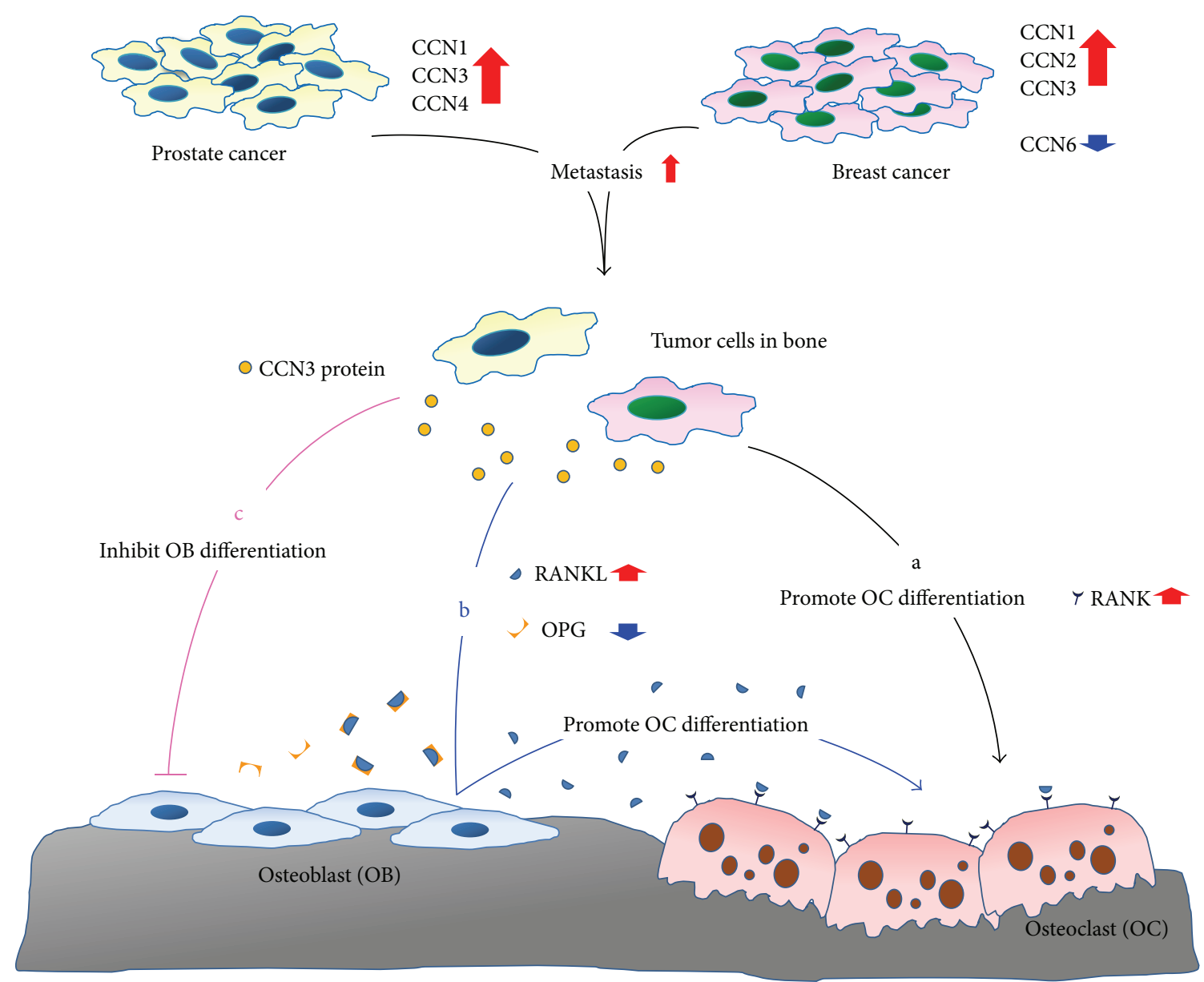

FIGURE 1: CCN family proteins involved in tumor metastasis and the mechanism of CCN3-modulated osteolytic bone metastasis. Tumors secrete different CCN proteins in prostate cancer (such as CCN1, CCN3, and CCN4) or breast cancer (such as CCN1, CCN2, CCN3, and CCN6) that regulate tumor metastasis. When tumor cells metastasize to the bone microenvironment, the secreted CCN protein (such as CCN3) promotes osteolytic bone metastasis in bone microenvironment through 3 different mechanisms. (a) CCN3 directly enhances osteoclasts formation through upregulating RANK expression, the crucial regulator of osteoclastogenesis. (b) CCN3 indirectly enhances osteoclast formation through affecting the RANKL/OPG secretion in osteoblasts, and the higher RANKL/OPG ratio increases the osteoclastogenesis. (c) CCN3 inhibits osteoblasts differentiation and thus reduces bone formation.

also proved that $\mathrm{CCN} 3$ enhanced osteoclast activity and bone metastasis in vivo.

$\mathrm{CCN} 4$ has been shown to play similar roles to $\mathrm{CCN} 3$ in prostate cancer [92]. An increased expression level of CCN4 has been found in prostate cancer tissue in the early stages, sera of patients, and carcinoma tissues of the mouse prostate cancer model TRAMP, which spontaneously develops to prostate carcinomas. Injections of CCN4 neutralizing antibodies were shown to reduce local tumor growth in a mouse xenograft model. These results suggest that CCN4 expression plays significant roles in both tumor growth and its metastasis to bone.

\section{Perspectives}

The CCN family proteins are multifunctional cytokines that regulate signals from the ECM. They are involved in many cellular processes and exert their functions through modulating various components including ECM proteins, transmembrane proteins, growth factors, and cytokines in the cell microenvironment. As they have crucial roles in osteo/chondrogenesis during development, abnormal expression of CCN proteins is implicated in tumors that grow in the bone microenvironment such as primary bone tumors and bone metastases. However, the roles of $\mathrm{CCN}$ proteins in osteo/chondrogenesis in development vary. The complicated interaction of $\mathrm{CCN}$ family proteins and other components outside the cells may contribute to unique activities and functions of $\mathrm{CCN}$ proteins. Emerging results suggest that the ultimate outcome of cellular responses modulated by CCN family proteins may also depend on the level of CCN expression. Although the available results suggest ambiguous roles of the CCN family proteins, they reveal the significance of $\mathrm{CCN}$ proteins in the regulation of bone homeostasis and turnover.

Interestingly, evidence on $\mathrm{CCN}$ family proteins in metastatic bone tumors indicates their pivotal role in bone microenvironment (Figure 1). However, there remains a lack 
of sufficient studies on CCN proteins in prostate and lung cancer metastasis to the bone. Further studies are required to confirm the molecular basis of CCN proteins in metastatic bone tumors. Moreover, the correlation and commonality of CCN proteins in metastatic bone tumors will help elucidate the importance of CCN family proteins in the bone microenvironment.

CTGF, one member of the CCN family associated with tumorigenesis, is a novel therapeutic target for the treatment of pancreatic cancer and is currently being investigated in a Phase I clinical trial. The results showed that twice weekly i.p. administration of FG-3019, a fully human CTGFspecific monoclonal antibody, decreased tumor growth and metastasis and attenuated tumor angiogenesis and cancer cell proliferation $[102,103]$. The other CCN proteins may use similar strategies to develop potential therapeutics which target $\mathrm{CCN}$ proteins and apply to bone tumor treatment.

\section{Conflict of Interests}

The authors declare that there is no conflict of interests regarding the publication of this paper.

\section{Acknowledgment}

This work was supported by Grant from the National Science Council of Taiwan (NSC100-2320-B-039-028-MY3, NSC1022632-B-039-001-MY3).

\section{References}

[1] A. Aszódi, K. R. Legate, I. Nakchbandi, and R. Fässler, "What mouse mutants teach us about extracellular matrix function," Annual Review of Cell and Developmental Biology, vol. 22, pp. 591-621, 2006.

[2] K. Y. Chen and C. H. Yao, "Repair of bone defects with gelatinbased composites: a review," BioMedicine, vol. 1, no. 1, pp. 29-32, 2011.

[3] P. Bornstein and E. H. Sage, "Matricellular proteins: extracellular modulators of cell function," Current Opinion in Cell Biology, vol. 14, no. 5, pp. 608-616, 2002.

[4] C.-C. Chen and L. F. Lau, "Functions and mechanisms of action of CCN matricellular proteins," International Journal of Biochemistry and Cell Biology, vol. 41, no. 4, pp. 771-783, 2009.

[5] A. Leask and D. J. Abraham, "All in the CCN family: essential matricellular signaling modulators emerge from the bunker," Journal of Cell Science, vol. 119, no. 23, pp. 4803-4810, 2006.

[6] K. P. Holbourn, K. R. Acharya, and B. Perbal, "The CCN family of proteins: structure-function relationships," Trends in Biochemical Sciences, vol. 33, no. 10, pp. 461-473, 2008.

[7] D. R. Brigstock, R. Goldschmeding, K.-I. Katsube et al., "Proposal for a unified CCN nomenclature," Journal of Clinical Pathology, vol. 56, no. 2, pp. 127-128, 2003.

[8] N. Planque and B. Perbal, "A structural approach to the role of CCN (CYR61/CTGF/NOV) proteins in tumourigenesis," Cancer Cell International, vol. 3, article 15, 2003.

[9] P. Bork, "The modular architecture of a new family of growth regulators related to connective tissue growth factor," FEBS Letters, vol. 327, no. 2, pp. 125-130, 1993.
[10] D. M. Bradham, A. Igarashi, R. L. Potter, and G. R. Grotendorst, "Connective tissue growth factor: a cysteine-rich mitogen secreted by human vascular endothelial cells is related to the SRC-induced immediate early gene product CEF-10," Journal of Cell Biology, vol. 114, no. 6, pp. 1285-1294, 1991.

[11] G. P. Yang and L. F. Lau, "Cyr61, product of a growth factorinducible immediate early gene, is associated with the extracellular matrix and the cell surface," Cell Growth \& Differentiation, vol. 2, no. 7, pp. 351-357, 1991.

[12] L. F. Lau and S. C.-T. Lam, "The CCN family of angiogenic regulators: the integrin connection," Experimental Cell Research, vol. 248, no. 1, pp. 44-57, 1999.

[13] A. W. Rachfal and D. R. Brigstock, "Structural and functional properties of CCN proteins," Vitamins and Hormones, vol. 70, pp. 69-103, 2005.

[14] H. Yeger and B. Perbal, "The CCN family of genes: a perspective on CCN biology and therapeutic potential," Journal of Cell Communication and Signaling, vol. 1, no. 3-4, pp. 159-164, 2007.

[15] J.-I. Jun and L. F. Lau, "Taking aim at the extracellular matrix: CCN proteins as emerging therapeutic targets," Nature Reviews Drug Discovery, vol. 10, no. 12, pp. 945-963, 2011.

[16] M. L. Kireeva, S. C.-T. Lam, and L. F. Lau, "Adhesion of human umbilical vein endothelial cells to the immediate- early gene product Cyr61 is mediated through integrin $\alpha_{v} \beta_{3}$," Journal of Biological Chemistry, vol. 273, no. 5, pp. 3090-3096, 1998.

[17] R. Gao and D. R. Brigstock, "A novel integrin $\alpha_{5} \beta_{1}$ binding domain in module 4 of connective tissue growth factor (CCN2/CTGF) promotes adhesion and migration of activated pancreatic stellate cells," Gut, vol. 55, no. 6, pp. 856-862, 2006.

[18] N. Chen, S.-J. Leu, V. Todorović, S. C.-T. Lam, and L. F. Lau, "Identification of a novel integrin $\alpha_{v} \beta_{3}$ binding site in CCN1 (CYR61) critical for pro-angiogenic activities in vascular endothelial cells," Journal of Biological Chemistry, vol. 279, no. 42, pp. 44166-44176, 2004.

[19] K. Sakamoto, S. Yamaguchi, R. Ando et al., "The nephroblastoma overexpressed gene $(\mathrm{NOV} / \mathrm{ccn} 3)$ protein associates with Notch1 extracellular domain and inhibits myoblast differentiation via Notch signaling pathway," Journal of Biological Chemistry, vol. 277, no. 33, pp. 29399-29405, 2002.

[20] T. Minamizato, K. Sakamoto, T. Liu et al., "CCN3/NOV inhibits BMP-2-induced osteoblast differentiation by interacting with BMP and Notch signaling pathways," Biochemical and Biophysical Research Communications, vol. 354, no. 2, pp. 567-573, 2007.

[21] C.-C. Chen, J. L. Young, R. I. Monzon, N. Chen, V. Todorović, and L. F. Lau, "Cytotoxicity of TNF $\alpha$ is regulated by integrinmediated matrix signaling," EMBO Journal, vol. 26, no. 5, pp. 1257-1267, 2007.

[22] Y. Chen, D. J. Abraham, X. Shi-Wen et al., "CCN2 (connective tissue growth factor) promotes fibroblast adhesion to fibronectin," Molecular Biology of the Cell, vol. 15, no. 12, pp. 5635-5646, 2004.

[23] T. Nishida, S. Kubota, T. Fukunaga et al., "CTGF/Hcs24, hypertrophic chondrocyte-specific gene product, interacts with perlecan in regulating the proliferation and differentiation of chondrocytes," Journal of Cellular Physiology, vol. 196, no. 2, pp. 265-275, 2003.

[24] V. Todorovi, C.-C. Chen, N. Hay, and L. F. Lau, "The matrix protein CCN1 (CYR61) induces apoptosis in fibroblasts," Journal of Cell Biology, vol. 171, no. 3, pp. 559-568, 2005.

[25] L. Desnoyers, D. Arnott, and D. Pennica, "WISP-1 binds to decorin and biglycan," Journal of Biological Chemistry, vol. 276, no. 50, pp. 47599-47607, 2001. 
[26] S. Mercurio, B. Latinkic, N. Itasaki, R. Krumlauf, and J. C. Smith, "Connective-tissue growth factor modulates WNT signalling and interacts with the WNT receptor complex," Development, vol. 131, no. 9, pp. 2137-2147, 2004.

[27] R. Gao and D. R. Brigstock, "Low density lipoprotein receptorrelated protein (LRP) is a heparin-dependent adhesion receptor for connective tissue growth factor (CTGF) in rat activated hepatic stellate cells," Hepatology Research, vol. 27, no. 3, pp. 214220, 2003.

[28] L. A. Edwards, K. Woolard, M. J. Son et al., "Effect of brainand tumor-derived connective tissue growth factor on glioma invasion," Journal of the National Cancer Institute, vol. 103, no. 15 , pp. 1162-1178, 2011.

[29] N. A. Wahab, B. S. Weston, and R. M. Mason, "Connective tissue growth factor CCN2 interacts with and activates the tyrosine kinase receptor TrkA," Journal of the American Society of Nephrology, vol. 16, no. 2, pp. 340-351, 2005.

[30] B. V. Perbal and M. Takigawa, CCN Proteins : A New family of Cell Growth and differentiation Regulators, Imperial College Press, London, UK, 2005.

[31] C.-C. Chen, N. Chen, and L. F. Lau, "The angiogenic factors Cyr61 and connective tissue growth factor induce adhesive signaling in primary human skin fibroblasts," Journal of Biological Chemistry, vol. 276, no. 13, pp. 10443-10452, 2001.

[32] H. Liu, W. Dong, Z. Lin et al., "CCN4 regulates vascular smooth muscle cell migration and proliferation," Molecules and Cells, vol. 36, no. 2, pp. 112-118, 2013.

[33] A. C. Lake and J. J. Castellot Jr., "CCN5 modulates the antiproliferative effect of heparin and regulates cell motility in vascular smooth muscle cells," Cell Communication and Signaling, vol. 1, article 5, 2003.

[34] N. Schütze, R. Schenk, J. Fiedler, T. Mattes, F. Jakob, and R. E. Brenner, "CYR61/CCN1 and WISP3/CCN6 are chemoattractive ligands for human multipotent mesenchymal stroma cells," BMC Cell Biology, vol. 8, article 45, 2007.

[35] S.-J. Leu, S. C.-T. Lam, and L. F. Lau, "Pro-angiogenic activities of CYR61 (CCN1) mediated through integrins $\alpha_{v} \beta_{3}$ and $\alpha_{6} \beta_{1}$ in human umbilical vein endothelial cells," Journal of Biological Chemistry, vol. 277, no. 48, pp. 46248-46255, 2002.

[36] M. L. Kireeva, F.-E. Mo, G. P. Yang, and L. F. Lau, "Cyr61, a product of a growth factor-inducible immediate-early gene, promotes cell proliferation, migration, and adhesion," Molecular and Cellular Biology, vol. 16, no. 4, pp. 1326-1334, 1996.

[37] G. Yosimichi, T. Nakanishi, T. Nishida, T. Hattori, T. TakanoYamamoto, and M. Takigawa, "Ctgf/hcs24 induces chondrocyte differentiation through a p38 mitogen-activated protein kinase (p38mapk), and proliferation through a p44/42 mapk/ extracellular-signal regulated kinase (erk)," European Journal of Biochemistry, vol. 268, no. 23, pp. 6058-6065, 2001.

[38] M. Baguma-Nibasheka and B. Kablar, "Pulmonary hypoplasia in the connective tissue growth factor (Ctgf) null mouse," Developmental Dynamics, vol. 237, no. 2, pp. 485-493, 2008.

[39] B. Perbal, "NOV (nephroblastoma overexpressed) and the CCN family of genes: structural and functional issues," Journal of Clinical Pathology, vol. 54, no. 2, pp. 57-79, 2001.

[40] G. W. Zuo, C. D. Kohls, B. C. He et al., "The CCN proteins: important signaling mediators in stem cell differentiation and tumorigenesis," Histology and Histopathology, vol. 25, no. 6, pp. 795-806, 2010.

[41] S. Kubota and M. Takigawa, "CCN family proteins and angiogenesis: from embryo to adulthood," Angiogenesis, vol. 10, no. 1, pp. 1-11, 2007.
[42] F.-E. Mo, A. G. Muntean, C.-C. Chen, D. B. Stolz, S. C. Watkins, and L. F. Lau, "CYR61 (CCN1) is essential for placental development and vascular integrity," Molecular and Cellular Biology, vol. 22, no. 24, pp. 8709-8720, 2002.

[43] S. Ivkovic, B. S. Yoon, S. N. Popoff et al., "Connective tissue growth factor coordinates chondrogenesis and angiogenesis during skeletal development," Development, vol. 130, no. 12, pp. 2779-2791, 2003.

[44] C. G. Lin, S.-J. Leu, N. Chen et al., "CCN3 (NOV) is a novel angiogenic regulator of the CCN protein family," Journal of Biological Chemistry, vol. 278, no. 26, pp. 24200-24208, 2003.

[45] L. Kular, J. Pakradouni, P. Kitabgi, M. Laurent, and C. Martinerie, "The CCN family: a new class of inflammation modulators?” Biochimie, vol. 93, no. 3, pp. 377-388, 2011.

[46] T. Bai, C.-C. Chen, and L. F. Lau, "Matricellular protein $\mathrm{CCN1}$ activates a proinflammatory genetic program in murine macrophages," Journal of Immunology, vol. 184, no. 6, pp. 32233232, 2010.

[47] M. Takigawa, T. Nakanishi, S. Kubota, and T. Nishida, "Role of CTGF/HCS24/ecogenin in skeletal growth control," Journal of Cellular Physiology, vol. 194, no. 3, pp. 256-266, 2003.

[48] Q. Luo, Q. Kang, W. Si et al., "Connective tissue growth factor (CTGF) is regulated by Wnt and bone morphogenetic proteins signaling in osteoblast differentiation of mesenchymal stem cells," Journal of Biological Chemistry, vol. 279, no. 53, pp. 5595855968, 2004.

[49] N. Schutze, U. Noth, J. Schneidereit, C. Hendrich, and F. Jakob, "Differential expression of CCN-family members in primary human bone marrow-derived mesenchymal stem cells during osteogenic, chondrogenic and adipogenic differentiation," Cell Communication and Signaling, vol. 3, article 5, 2005.

[50] W. Si, Q. Kang, H. H. Luu et al., "CCN1/Cyr61 is regulated by the canonical Wnt signal and plays an important role in Wnt3Ainduced osteoblast differentiation of mesenchymal stem cells," Molecular and Cellular Biology, vol. 26, no. 8, pp. 2955-2964, 2006.

[51] V. Ouellet and P. M. Siegel, "CCN3 modulates bone turnover and is a novel regulator of skeletal metastasis," Journal of Cell Communication and Signaling, vol. 6, no. 2, pp. 73-85, 2012.

[52] M. Wong, M. L. Kireeva, T. V. Kolesnikova, and L. F. Lau, "Cyr61, product of a growth factor-inducible immediate-early gene, regulates chondrogenesis in mouse limb bud mesenchymal cells," Developmental Biology, vol. 192, no. 2, pp. 492-508, 1997.

[53] J. C. Crockett, N. Schütze, D. Tosh et al., "The matricellular protein CYR61 inhibits osteoclastogenesis by a mechanism independent of $\alpha_{v} \beta_{3}$ and $\alpha_{v} \beta_{5}$," Endocrinology, vol. 148, no. 12, pp. 5761-5768, 2007.

[54] K.-I. Katsube, K. Sakamoto, Y. Tamamura, and A. Yamaguchi, "Role of CCN, a vertebrate specific gene family, in development," Development Growth and Differentiation, vol. 51, no. 1, pp. 55-67, 2009.

[55] T. Nishida, T. Nakanishi, M. Asano et al., "Effects of CTGF/Hcs24, a hypertrophic chondrocyte-specific gene product, on the proliferation and differentiation of osteoblastic cells in vitro," Journal of Cellular Physiology, vol. 184, no. 2, pp. 197-206, 2000

[56] T. Shimo, M. Kanyama, C. Wu et al., "Expression and roles of connective tissue growth factor in Meckel's cartilage development," Developmental Dynamics, vol. 231, no. 1, pp. 136-147, 2004.

[57] S. Maeda, "An impact of CCN2-BMP-2 complex upon chondrocyte biology: evoking a signalling pathway bypasses ERK and 
Smads?" Journal of Biochemistry, vol. 150, no. 3, pp. 219-221, 2011.

[58] J. G. Abreu, N. I. Ketpura, B. Reversade, and E. M. De Robertis, "Connective-tissue growth factor (CTGF) modulates cell signalling by BMP and TGF- $\beta$," Nature Cell Biology, vol. 4, no. 8, pp. 599-604, 2002.

[59] S. Rydziel, L. Stadmeyer, S. Zanotti, D. Durant, A. SmerdelRamoya, and E. Canalis, "Nephroblastoma overexpressed (Nov) inhibits osteoblastogenesis and causes osteopenia," Journal of Biological Chemistry, vol. 282, no. 27, pp. 19762-19772, 2007.

[60] E. Canalis, "Nephroblastoma overexpressed (Nov) is a novel bone morphogenetic protein antagonist," Annals of the New York Academy of Sciences, vol. 1116, pp. 50-58, 2007.

[61] T.-W. Tan, Y.-L. Huang, J.-T. Chang et al., "CCN3 increases BMP-4 expression and bone mineralization in osteoblasts," Journal of Cellular Physiology, vol. 227, no. 6, pp. 2531-2541, 2012.

[62] A. A. Sabile, M. J. E. Arlt, R. Muff et al., "Cyr61 expression in osteosarcoma indicates poor prognosis and promotes intratibial growth and lung metastasis in mice," Journal of Bone and Mineral Research, vol. 27, no. 1, pp. 58-67, 2012.

[63] O. Fromigue, Z. Hamidouche, P. Vaudin et al., "CYR61 downregulation reduces osteosarcoma cell invasion, migration, and metastasis," Journal of Bone and Mineral Research, vol. 26, no. 7, pp. 1533-1542, 2011.

[64] M. C. Manara, B. Perbal, S. Benini et al., "The expression of CCN3(NOV) gene in musculoskeletal tumors," The American Journal of Pathology, vol. 160, no. 3, pp. 849-859, 2002.

[65] C. L. Wu, H. C. Tsai, Z. W. Chen et al., "Ras activation mediates WISP-1-induced increases in cell motility and matrix metalloproteinase expression in human osteosarcoma," Cellular Signalling, vol. 25, no. 12, pp. 2812-2822, 2013.

[66] B. Perbal, N. Lazar, D. Zambelli et al., "Prognostic relevance of CCN3 in Ewing sarcoma," Human Pathology, vol. 40, no. 10, pp. 1479-1486, 2009.

[67] S. Benini, B. Perbal, D. Zambelli et al., "In Ewing's sarcoma $\mathrm{CCN} 3(\mathrm{NOV})$ inhibits proliferation while promoting migration and invasion of the same cell type," Oncogene, vol. 24, no. 27, pp. 4349-4361, 2005.

[68] T.-W. Tan, W.-H. Yang, Y.-T. Lin et al., "Cyr61 increases migration and MMP-13 expression via $\alpha_{v} \beta_{3}$ integrin, FAK, ERK and AP-1-dependent pathway in human chondrosarcoma cells," Carcinogenesis, vol. 30, no. 2, pp. 258-268, 2009.

[69] T.-W. Tan, C.-H. Lai, C.-Y. Huang et al., "CTGF enhances migration and MMP-13 up-regulation via $\alpha_{v} \beta_{3}$ integrin, FAK, $\mathrm{ERK}$, and NF- $\kappa \mathrm{B}$-dependent pathway in human chondrosarcoma cells," Journal of Cellular Biochemistry, vol. 107, no. 2, pp. 345-356, 2009.

[70] H.-E. Tzeng, J.-C. Chen, C.-H. Tsai et al., "CCN3 increases cell motility and MMP-13 expression in human chondrosarcoma through integrin-dependent pathway," Journal of Cellular Physiology, vol. 226, no. 12, pp. 3181-3189, 2011.

[71] C.-H. Hou, Y.-C. Chiang, Y.-C. Fong, and C.-H. Tang, "WISP1 increases MMP-2 expression and cell motility in human chondrosarcoma cells," Biochemical Pharmacology, vol. 81, no. 11, pp. 1286-1295, 2011.

[72] Y.-C. Fong, C.-Y. Lin, Y.-C. Su et al., "CCN6 enhances ICAM-1 expression and cell motility in human chondrosarcoma cells," Journal of Cellular Physiology, vol. 227, no. 1, pp. 223-232, 2012.

[73] T. A. Damron, W. G. Ward, and A. Stewart, "Osteosarcoma, chondrosarcoma, and Ewing's sarcoma: national cancer data base report," Clinical Orthopaedics and Related Research, no. 459, pp. 40-47, 2007.
[74] H. D. Dorfman and B. Czerniak, "Bone cancers," Cancer, vol. 75, no. 1, pp. 203-210, 1995.

[75] R. Sweetnam, "Osteosarcoma," British Journal of Hospital Medicine, vol. 28, no. 2, pp. 112-121, 1982.

[76] R. M. Terek, G. K. Schwartz, K. Devaney et al., "Chemotherapy and P-glycoprotein expression in chondrosarcoma," Journal of Orthopaedic Research, vol. 16, no. 5, pp. 585-590, 1998.

[77] C. H. Tang, "Molecular mechanisms of chondrosarcoma metastasis," BioMedicine, vol. 2, no. 3, pp. 92-98, 2012.

[78] C. A. Hamm, J. W. Stevens, H. Xie et al., "Microenvironment alters epigenetic and gene expression profiles in Swarm rat chondrosarcoma tumors," BMC Cancer, vol. 10, article 471, 2010.

[79] W. G. Jiang, G. Watkins, O. Fodstad, A. Douglas-Jones, K. Mokbel, and R. E. Mansel, "Differential expression of the CCN family members Cyr61, CTGF and Nov in human breast cancer," Endocrine-Related Cancer, vol. 11, no. 4, pp. 781-791, 2004.

[80] I. Espinoza, H. Liu, R. Busby, and R. Lupu, "CCN1, a candidate target for zoledronic acid treatment in breast cancer," Molecular Cancer Therapeutics, vol. 10, no. 5, pp. 732-741, 2011.

[81] J. Lin, R. Huo, L. Wang et al., "A novel anti-Cyr61 antibody inhibits breast cancer growth and metastasis in vivo," Cancer Immunology, Immunotherapy, vol. 61, no. 5, pp. 677-687, 2012.

[82] S. Casimiro, I. Luis, A. Fernandes et al., "Analysis of a bone metastasis gene expression signature in patients with bone metastasis from solid tumors," Clinical and Experimental Metastasis, vol. 29, no. 2, pp. 155-164, 2012.

[83] T. R. Cawthorn, E. Amir, R. Broom et al., "Mechanisms and pathways of bone metastasis: challenges and pitfalls of performing molecular research on patient samples," Clinical and Experimental Metastasis, vol. 26, no. 8, pp. 935-943, 2009.

[84] T. Shimo, S. Kubota, N. Yoshioka et al., "Pathogenic role of connective tissue growth factor (CTGF/CCN2) in osteolytic metastasis of breast cancer," Journal of Bone and Mineral Research, vol. 21, no. 7, pp. 1045-1059, 2006.

[85] Y. Kang, P. M. Siegel, W. Shu et al., "A multigenic program mediating breast cancer metastasis to bone," Cancer Cell, vol. 3, no. 6, pp. 537-549, 2003.

[86] X. H.-F. Zhang, Q. Wang, W. Gerald et al., "Latent bone metastasis in breast cancer tied to Src-dependent survival signals," Cancer Cell, vol. 16, no. 1, pp. 67-78, 2009.

[87] V. Ouellet, K. Tiedemann, A. Mourskaia et al., "CCN3 impairs osteoblast and stimulates osteoclast differentiation to favor breast cancer metastasis to bone," The American Journal of Pathology, vol. 178, no. 5, pp. 2377-2388, 2011.

[88] A. Pal, W. Huang, X. Li et al., "CCN6 modulates BMP signaling via the Smad-independent TAK1/p38 pathway, acting to suppress metastasis of breast cancer," Cancer Research, vol. 72, no. 18, pp. 4818-4828, 2012.

[89] Z.-J. Sun, Y. Wang, Z. Cai, P.-P. Chen, X.-J. Tong, and D. Xie, "Involvement of Cyr61 in growth, migration, and metastasis of prostate cancer cells," British Journal of Cancer, vol. 99, no. 10, pp. 1656-1667, 2008.

[90] P.-C. Chen, T.-H. Lin, H.-C. Cheng, and C.-H. Tang, "CCN3 increases cell motility and ICAM-1 expression in prostate cancer cells," Carcinogenesis, vol. 33, no. 4, pp. 937-945, 2012.

[91] P. C. Chen, H. C. Cheng, and C. H. Tang, "CCN3 promotes prostate cancer bone metastasis by modulating the tumorbone microenvironment through RANKL-dependent pathway," Carcinogenesis, vol. 34, no. 7, pp. 1669-1679, 2013.

[92] M. Ono, C. A. Inkson, R. Sonn et al., "WISP1/CCN4: a potential target for inhibiting prostate cancer growth and spread to bone," PLoS ONE, vol. 8, no. 8, Article ID e71709, 2013. 
[93] R. E. Coleman, R. Roodman, S. Smith, B. Body, S. Suva, and V. Vessella, "Clinical features of metastatic bone disease and risk of skeletal morbidity," Clinical Cancer Research, vol. 12, no. 20, pp. 6243s-6249s, 2006.

[94] L. G. Harris, L. K. Pannell, S. Singh, R. S. Samant, and L. A. Shevde, "Increased vascularity and spontaneous metastasis of breast cancer by hedgehog signaling mediated upregulation of cyr61," Oncogene, vol. 31, pp. 3370-3380, 2012.

[95] W. Huang, M. E. Gonzalez, K. A. Toy, M. Banerjee, and C. G. Kleer, "Blockade of CCN6 (WISP3) activates growth factor-independent survival and resistance to anoikis in human mammary epithelial cells," Cancer Research, vol. 70, no. 8, pp. 3340-3350, 2010.

[96] R. B. Shah, R. Mehra, A. M. Chinnaiyan et al., "Androgenindependent prostate cancer is a heterogeneous group of diseases: lessons from a rapid autopsy program," Cancer Research, vol. 64, no. 24, pp. 9209-9216, 2004.

[97] R. J. Bryant and F. C. Hamdy, "Screening for prostate cancer: an update," European Urology, vol. 53, no. 1, pp. 37-44, 2008.

[98] B. Cipolla, J. Y. Bansard, J. P. Ecalard et al., "Treating metastatic castration-resistant prostate cancer with novel polyamine-free oral nutritional supplementation: phase I study," BioMedicine, vol. 3, no. 3, pp. 114-119, 2013.

[99] S. R. Larson, X. Zhang, R. Dumpit et al., "Characterization of osteoblastic and osteolytic proteins in prostate cancer bone metastases," Prostate, vol. 73, no. 9, pp. 932-940, 2013.

[100] E. T. Keller and J. Brown, "Prostate cancer bone metastases promote both osteolytic and osteoblastic activity," Journal of Cellular Biochemistry, vol. 91, no. 4, pp. 718-729, 2004.

[101] M. P. Roudier, L. D. True, C. S. Higano et al., "Phenotypic heterogeneity of end-stage prostate carcinoma metastatic to bone," Human Pathology, vol. 34, no. 7, pp. 646-653, 2003.

[102] N. Dornhöfer, S. Spong, K. Bennewith et al., "Connective tissue growth factor-specific monoclonal antibody therapy inhibits pancreatic tumor growth and metastasis," Cancer Research, vol. 66, no. 11, pp. 5816-5827, 2006.

[103] T. Aikawa, J. Gunn, S. M. Spong, S. J. Klaus, and M. Korc, "Connective tissue growth factor-specific antibody attenuates tumor growth, metastasis, and angiogenesis in an orthotopic mouse model of pancreatic cancer," Molecular Cancer Therapeutics, vol. 5, no. 5, pp. 1108-1116, 2006. 

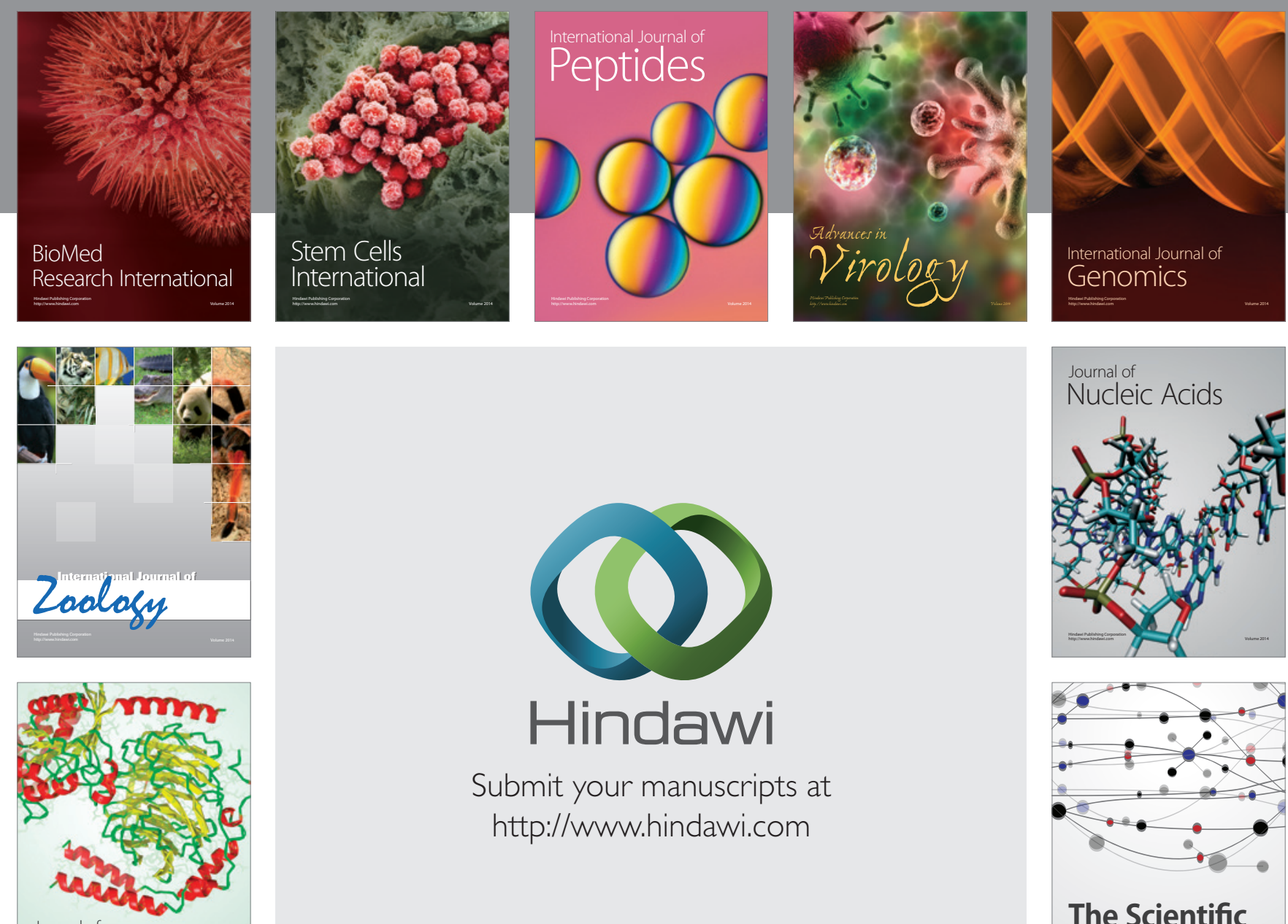

Submit your manuscripts at

http://www.hindawi.com

Journal of
Signal Transduction
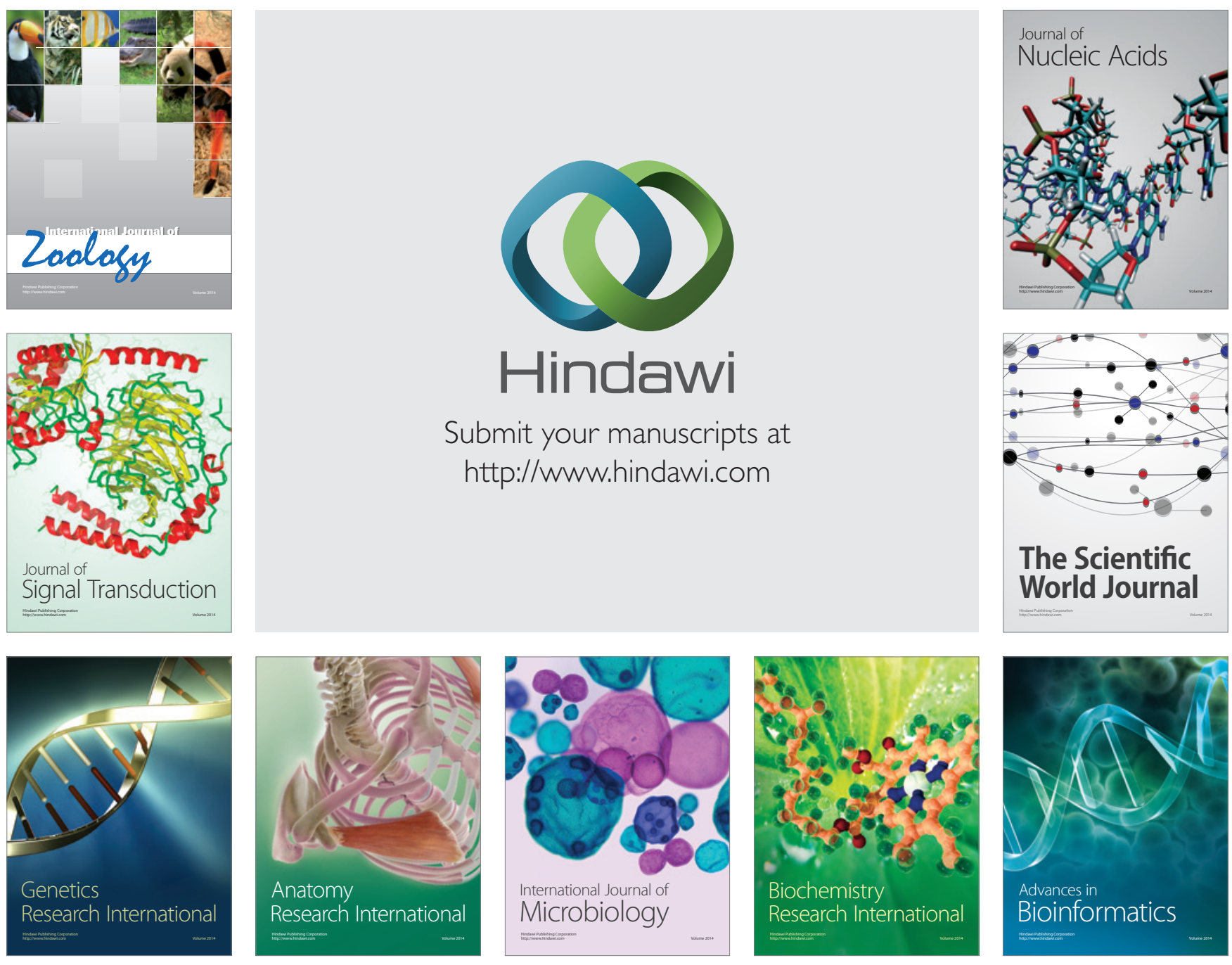

The Scientific World Journal
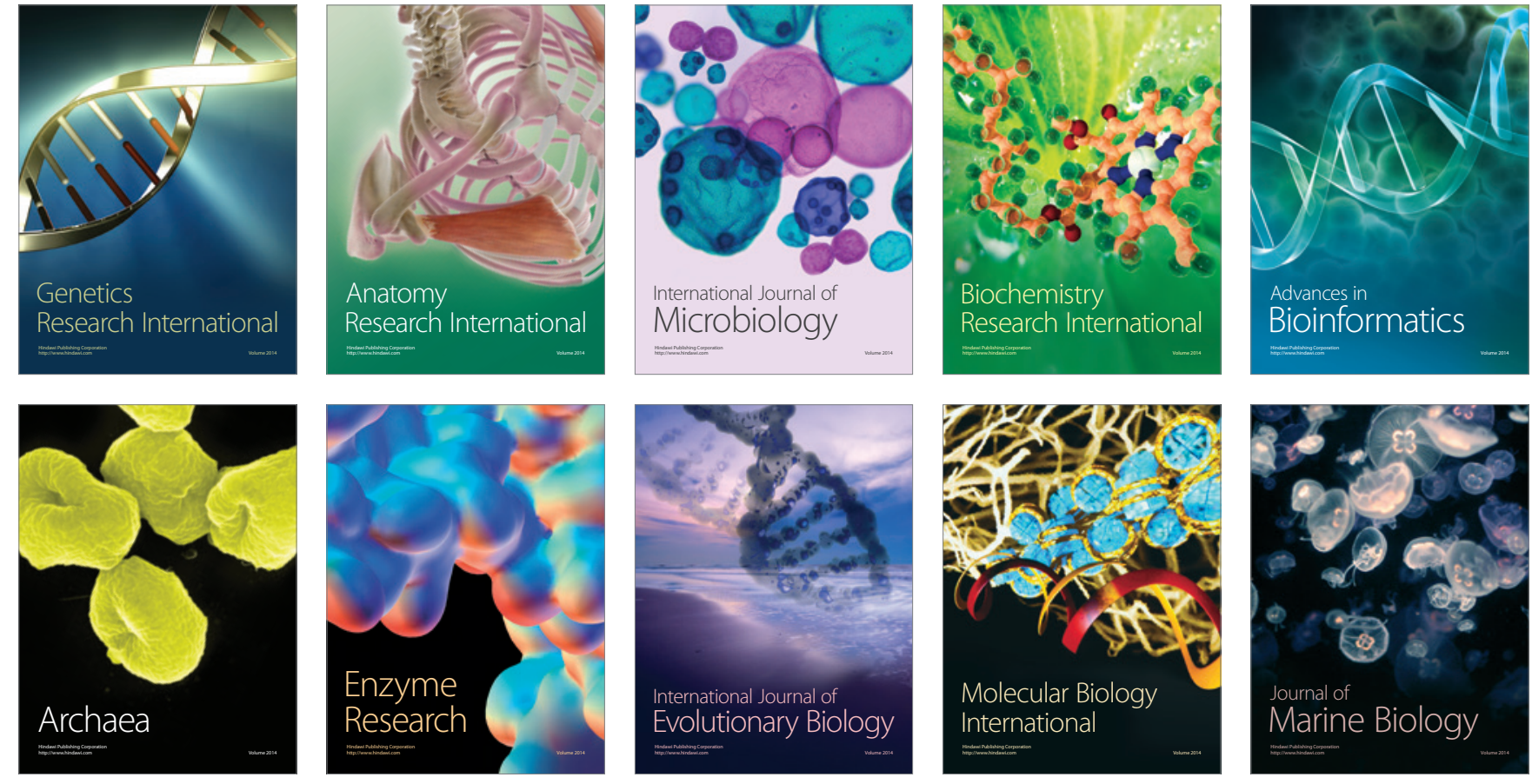